\title{
Correction to: A Case of Two Adult Brothers with Wiskott-Aldrich Syndrome, One Treated with Gene Therapy and One with HLA-Identical Hematopoietic Stem Cell Transplantation
}

\author{
Giulia Consiglieri $^{1,2} \cdot$ Francesca Ferrua $^{1,2} \cdot$ San Raffaele Hospital Consortium $\cdot$ Alessandro Aiuti ${ }^{1,2,3}$. \\ Maria Pia Cicalese ${ }^{1,2}$
}

Published online: 8 December 2021

๑) Springer Science+Business Media, LLC, part of Springer Nature 2021

\section{Correction to: Journal of Clinical Immunology} https://doi.org/10.1007/s10875-021-01157-6

Due to typesetting mistake, some entries of Table 1 were not properly aligned to their corresponding rows.

The original version has been corrected.

Publisher's Note Springer Nature remains neutral with regard to jurisdictional claims in published maps and institutional affiliations.

The original article can be found online at https://doi.org/10.1007/ s10875-021-01157-6.

Alessandro Aiuti aiuti.alessandro@hsr.it

1 Pediatric Immunohematology and Bone Marrow Transplantation Unit, IRCCS San Raffaele Scientific Institute, Milan, Italy

2 San Raffaele Telethon Institute for Gene Therapy (SR-Tiget), IRCCS San Raffaele Scientific Institute, Milan, Italy

3 Vita-Salute San Raffaele University, Milan, Italy 